\title{
Lithium lanthanum titanate perovskite ionic conductor: Influence of europium doping on structural and optical properties
}

\author{
Silvia Leticia Fernandes ${ }^{\mathrm{a}, *}$, Gisele Gasparotto ${ }^{\mathrm{a}}$, Guilhermina Ferreira Teixeira ${ }^{\mathrm{a}}$, \\ Marco Aurélio Cebim ${ }^{\mathrm{a}}$, Elson Longo ${ }^{\mathrm{b}}$, Maria Aparecida Zaghete ${ }^{\mathrm{a}}$

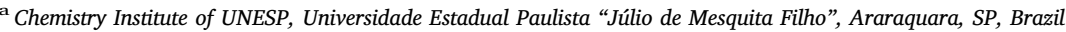 \\ ${ }^{\mathrm{b}}$ UFSCAR, Federal University of São Carlos, Chemistry Department, São Carlos, SP, Brazil
}

\section{A R T I C L E I N F O}

\section{Keywords:}

B. Perovskite

C. Photoluminescence

D. Lithium lanthanum titanate

E. Lithium battery

\begin{abstract}
A B S T R A C T
The present study reports the insertion of europium ions into the network of lithium lanthanum titanate, $\mathrm{La}_{0.5} \mathrm{Li}_{0.5} \mathrm{TiO}_{3}$, powders. The materials were prepared efficiently via the Pechini method and were characterized using thermogravimetric analyses, X-ray diffraction, high-resolution electron microscopy and photoluminescence spectroscopy. The results obtained demonstrate the high structural disorder of $\mathrm{La}_{0.5} \mathrm{Li}_{0.5} \mathrm{TiO}_{3}$ (LLTO) as well as the different environments noticed by $\mathrm{Eu}^{3+}$ ions in the $\mathrm{La}_{0.5} \mathrm{Li}_{0.5} \mathrm{TiO}_{3}$ host lattice. Our results are essentially important once they unfold a better understanding of the complex nature of $\mathrm{La}_{0.5} \mathrm{Li}_{0.5} \mathrm{TiO}_{3}$ compounds structure.
\end{abstract}

\section{Introduction}

$\mathrm{La}_{2 / 3-x} \mathrm{Li}_{3 \times} \mathrm{TiO}_{3}$ system has been extensively studied for use in lithium batteries as electrodes, solid electrolytes and as separators in lithium-air batteries as a result of its high ion mobility, which can reach up to $10^{-3} \mathrm{~S} \mathrm{~cm}^{-1}$ at room temperature [1-3]. Based on the work conducted by Inaguma et al. [4] which reported high mobility of lithium ions in $\mathrm{La}_{0.55} \mathrm{Li}_{0.35} \mathrm{TiO}_{3}$ composition, several mechanisms for the conduction of $\mathrm{La}_{2 / 3-\mathrm{x}} \mathrm{Li}_{3 \times} \times \mathrm{TiO}_{3}$ compounds have since been proposed associated mainly with structural considerations, conductivity measurements and theoretical models aiming at justifying the high ionic conductivity at room temperature [5-14]. Despite considerable understanding has been achieved in LLTO compounds, detailed comprehension of lithium ion diffusion as well as the influence of composition and associated local structural changes on diffusion is still lacking [14]. In fact since the different crystal structures obtained (including simple cubic [15-17], hexagonal [18], tetragonal [19-21] and orthorhombic $[21,22])$ depend on the method of synthesis used, and the conductivity is related to the structure, it is possible to control the conductivity indirectly via the synthesis.

Most of the authors assume that the high ionic conductivity stems from the presence of vacancies on $\mathrm{La}_{2 / 3-\mathrm{x}} \mathrm{Li}_{3 \times} \times \mathrm{TiO}_{3}$ sites, favoring the mobility of $\mathrm{Li}^{+}$ions through the structure. Thus, the position of $\mathrm{Li}^{+}$ ions is of crucial importance in explaining the ionic conductivity in $\mathrm{La}_{2}$ / 3-x $\mathrm{Li}_{3 \times} \mathrm{TiO}_{3}$ compounds which is directly related to the occupancy of the interstitial spaces by $\mathrm{Li}^{+}[23]$.

The replacement of the elements $\mathrm{A}$ or $\mathrm{B}$ from the $\mathrm{ABO}_{3}$ perovskite structure of $\mathrm{La}_{2 / 3-x} \mathrm{Li}_{3} \times \mathrm{TiO}_{3}$ is carried out aiming at improving the ionic conductivity of these materials. A number of studies have reported a complete or partial substitution of $\mathrm{La}^{3+}$ with other lanthanide ions including Pr, Nd and Sm, where it was observed that this substitution is accompanied by distortions in the perovskite lattice. These distortions are known to be responsible for the reduction of the so-called "bottlenecks". As the bottlenecks are the path by which Li ions move, their reduction is seen to account for the decrease in ionic conductivity [23].

Similarly, the lanthanide $\mathrm{Eu}^{3+}$ is found to be capable of replacing $\mathrm{La}^{3+}$ ions from $\mathrm{La}_{2 / 3-x} \mathrm{Li}_{3 \times} \mathrm{TiO}_{3}$ and be used as structural probe. The electronic transitions located in their luminescent centers indicate the ionic properties of the matrix in which it is contained as well as the interaction $\mathrm{Eu}^{3+} /$ matrix. Hence, the use of lanthanides as structural probe provides information regarding the symmetry of the crystallographic sites, the nature of the chemical bonds (covalent grade), the energy transfer processes and the long range symmetry effect of the spectroscopic properties of the luminescent centers [24-31].

In this work, the replacement of $\mathrm{La}^{3+}$ with $\mathrm{Eu}^{3+}$ was done with the purpose of understanding the complex structure of $\mathrm{La}_{0.5} \mathrm{Li}_{0.5} \mathrm{TiO}_{3}$ and the location of the ions in the crystal lattice for a better knowledge of the ionic conductivity in $\mathrm{La}_{2 / 3-\mathrm{x}} \mathrm{Li}_{3 \times} \mathrm{TiO}_{3}$.

\footnotetext{
* Corresponding author.

E-mail address: sy.fernandes@hotmail.com (S.L. Fernandes).
} 


\section{Methodology}

$\mathrm{La}_{0.5} \mathrm{Li}_{0.5} \mathrm{TiO}_{3}$ powders which are nominally pure and $\mathrm{Eu}^{3+}$-doped $(0.1,0.25,0.5$ and 1 at $\%)$ were obtained by the Pechini method. Titanium (IV) isopropoxide, Ti[OCH( $\left.\left(\mathrm{CH}_{3}\right)_{2}\right]_{4}$ (Alfa Aesar), lithium nitrate, $\mathrm{LiNO}_{3}$ (Vetec), lanthanum nitrate, $\mathrm{La}\left(\mathrm{NO}_{3}\right)_{3} \cdot 6 \mathrm{H}_{2} \mathrm{O}$ (Vetec), europium oxide, $\mathrm{Eu}_{2} \mathrm{O}_{3}$ (Sigma Aldrich), citric acid, $\mathrm{C}_{6} \mathrm{H}_{8} \mathrm{O}_{7}$ (Sigma Aldrich) and ethylene glycol, $\mathrm{C}_{2} \mathrm{H}_{6} \mathrm{O}_{2}$ (Sigma Aldrich) were used for the synthesis. The molar ratio of the chemicals was defined based on the Pechini method [32]: $1 \mathrm{~mol}$ of metal: $4 \mathrm{~mol}$ of citric acid: $16 \mathrm{~mol}$ of ethylene glycol. The precursors were mixed, stirred and heated at $120^{\circ} \mathrm{C}$ for $1 \mathrm{~h}$, followed by heat treatment at $350{ }^{\circ} \mathrm{C}$ for $2 \mathrm{~h}$ (precursor powders). The final material was slowly burned at $800{ }^{\circ} \mathrm{C}$ for $3 \mathrm{~h}$. The precursor powders were characterized by thermogravimetry (TG) and differential thermal analysis (DTA) using a Netszch-Thermische Analyse (PU 1.851.01 and TASC 414/2 controller). $\alpha-\mathrm{Al}_{2} \mathrm{O}_{3}$ was used as a standard material and the samples were placed in alumina crucibles using a $10 \mathrm{Pt}$ thermocouple (Pt / Pt $10 \% \mathrm{Rh}$ ) and subjected to a heating rate of $10{ }^{\circ} \mathrm{C} /$ min and synthetic air flow of $30 \mathrm{~cm}^{3} / \mathrm{min}$. The X-ray diffraction (XRD) measurements were performed using a Rigaku/RINT2000, 20-80 ${ }^{\circ}$ with an increment of $0.20^{\circ} / \mathrm{min}, \mathrm{Cu}-\mathrm{K \alpha}$ radiation. The FEG-VP Zeiss Supra 35 model was used for the FE-SEM (high resolution field emission gun scanning electron microscopy) measurements. Optical measurements were performed by photoluminescence (PL) using a Thermal Jarrell-Ash Monospec 27 monochromator and a Hamamatsu R446 photomultiplier. A krypton ion laser (Coherent Innova) with an exciting wavelength of $350 \mathrm{~nm}$ was used, with the nominal output power of the laser kept at $550 \mathrm{~mW}$. UV-Vis measurements were performed using a LAMBA 1050 PerkinElmer spectrophotometer and Raman spectra were collected with a triple monochromator T-64000 HORIBA Jobin-Yvon (USA) coupled to a CCD detector with excitation of $514.4 \mathrm{~nm}$ from an argon ion laser and input power of $8 \mathrm{~mW}$. All measurements were performed at room temperature.

\section{Results and discussion}

The heating process of the polymeric precursor method involves a great loss of mass. TG curve of $\mathrm{La}_{0.5} \mathrm{Li}_{0.5} \mathrm{TiO}_{3}$ precursor powders (Fig. 1a) indicates a mass loss of approximately $70 \%$ between $25^{\circ} \mathrm{C}$ and $900{ }^{\circ} \mathrm{C}$, while the curve of $\mathrm{La}_{0.5} \mathrm{Li}_{0.5} \mathrm{TiO}_{3}: \mathrm{Eu}^{3+}$ (Fig. 2a) shows a mass loss of approximately $60 \%$ between $25^{\circ} \mathrm{C}$ and $900^{\circ} \mathrm{C}$. The mass loss during the heat treatment refers to the removal of solvent and water, the decomposition of the polyester chain and carboxyl groups linked to the metal with a consequent formation of crystalline metal-oxygen phase.

DTA curves (Fig. 1a and Fig. 2a) show both endothermic and exothermic processes involved in the decomposition of the polyester. Endothermic processes, for temperatures below $200{ }^{\circ} \mathrm{C}$, are associated with the loss of the excess of ethylene glycol and water. The exothermic process is seen beginning at $450{ }^{\circ} \mathrm{C}$. A maximum heat is found to be released at $500{ }^{\circ} \mathrm{C}$ relating to the decomposition of the polyester chain. The formation of the metal-oxygen bonds is observed from $500{ }^{\circ} \mathrm{C}$ onwards, giving rise to the formation of the perovskite phase of lithium lanthanum titanate $-\mathrm{La}_{0.5} \mathrm{Li}_{0.5} \mathrm{TiO}_{3}$.

Figs. $1 \mathrm{~b}$ and $2 \mathrm{~b}$ present FE-SEM images of the non-doped and doped materials, respectively. These images reveal aggregated nanoparticles with a spherical shape. It can be observed that the doped powder has larger particles, which are found to be more agglomerated and with sintering traces compared to the non-doped powders. The addition of $\mathrm{Eu}^{3+}$, in effect, promotes distortions and instability in the network frame, thus favoring the sintering process.

The XRD patterns of non-doped $\mathrm{La}_{0.5} \mathrm{Li}_{0.5} \mathrm{TiO}_{3}$ powders are shown in Fig. 1c. The powders treated at $350{ }^{\circ} \mathrm{C}$ are amorphous. The formation of $\mathrm{La}_{0.5} \mathrm{Li}_{0.5} \mathrm{TiO}_{3}$ crystalline phase (JCPDS 01-070-6720) can be observed at $700^{\circ} \mathrm{C}$. The powders heated at $800^{\circ} \mathrm{C}$ are found to exhibit high crystallinity and this outcome suggests that in the temperature range studied, the increase observed in the annealing temperature improves the crystallinity of the perovskite phase. It is therefore evidently clear the existence of a correlation between the crystallization processes of $\mathrm{La}_{0.5} \mathrm{Li}_{0.5} \mathrm{TiO}_{3}$ phase and the removal of the organic components. A careful analysis of the diffraction patterns revealed the presence of the secondary phase of $\mathrm{Li}_{2} \mathrm{TiO}_{3}$ (JCPDS 00-033-0831) denoted in the diffraction patterns with the symbol $(*)$ at $2 \theta=30.2^{\circ}$ and $2 \theta=43.5^{\circ}$.

The XRD results of the $\mathrm{Eu}^{3+}$ doped powders are shown in Fig. 2c. It is worth pointing out that no changes were observed in the diffractions peaks when $\mathrm{La}_{0.5} \mathrm{Li}_{0.5} \mathrm{TiO}_{3}$ was doped with $\mathrm{Eu}^{3+}$ as compared to the nominally pure material; $\mathrm{Eu}^{3+}$ was inserted in the crystalline network of the $\mathrm{La}_{0.5} \mathrm{Li}_{0.5} \mathrm{TiO}_{3}$ and no secondary phase regarding $\mathrm{Eu}^{3+}$ doping was observed. Furthermore, no changes are observed in the XRD of the material doped with varying concentrations of $\mathrm{Eu}^{3+}$ ion.

Raman measurements were evaluated in order to obtain additional information regarding the short range structural ordering of LLTO samples. The spectra (Fig. 3) show seven bands located at 140, 230, $320,360,400,530$ and $660 \mathrm{~cm}^{-1}$. The bands around 140, 230 and $530 \mathrm{~cm}^{-1}$ can be assigned to Eg modes while the $A_{1 \mathrm{~g}}$ mode is found at $320 \mathrm{~cm}^{-1}$. [33] According to Sanjuán et al. [34] the bands near to 140 and $320 \mathrm{~cm}^{-1}$ are present in the spectra mostly in plane and c-axis titanium vibration, respectively, and the other modes exist due to the oxygen motion. Bands located around 360,400 and $660 \mathrm{~cm}^{-1}$ are present in lithium titanates Raman spectra $[35,36]$ thus the presence of these bands in our Raman spectra is in agreement whit our XRD results, which revealed the presence of $\mathrm{Li}_{2} \mathrm{TiO}_{3}$ as a secondary phase. Regarding
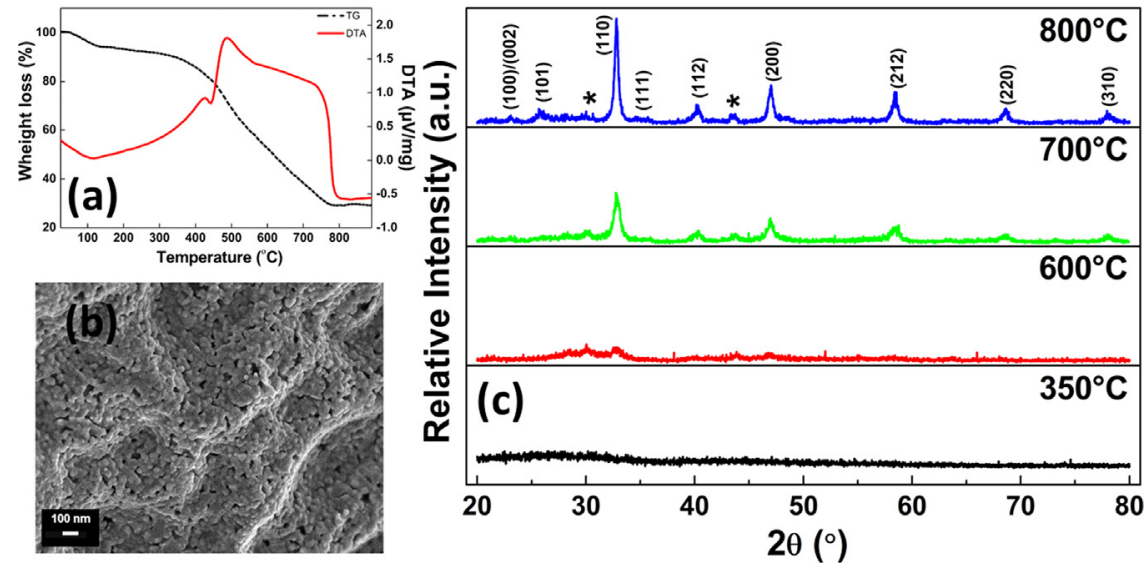

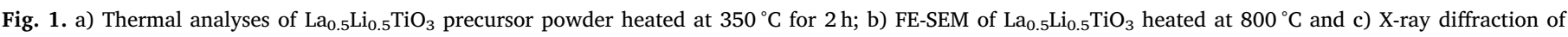
$\mathrm{La}_{0.5} \mathrm{Li}_{0.5} \mathrm{TiO}_{3}$ heated at varying temperatures. 

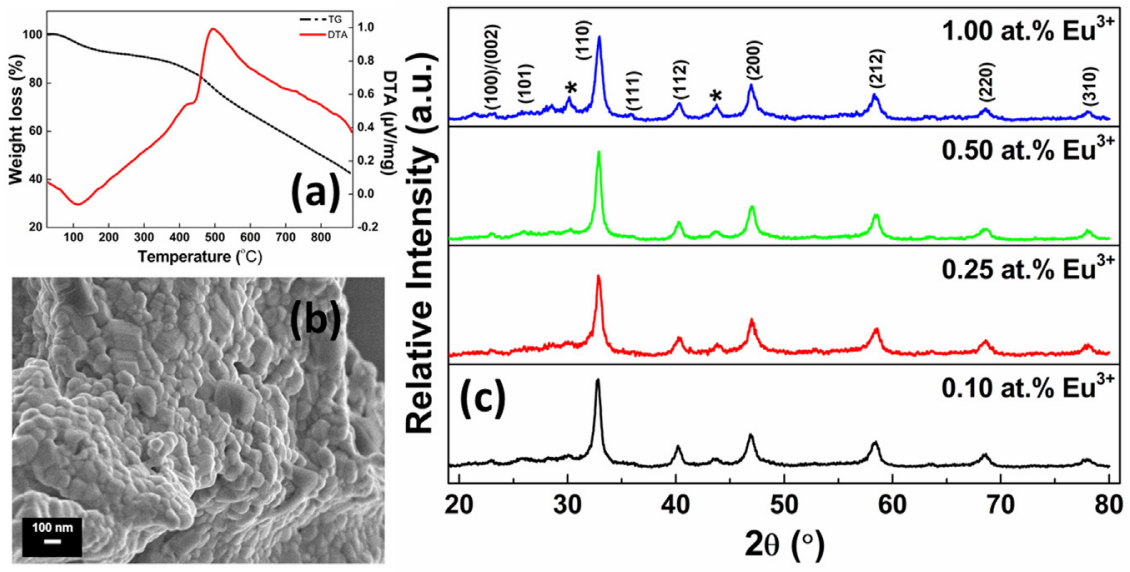

Fig. 2. a) Thermal analyses of $\mathrm{La}_{0.5} \mathrm{Li}_{0.5} \mathrm{TiO}_{3}: \mathrm{Eu}^{3+}$ (1 at $\left.\%\right)$ precursor powder heated at $350{ }^{\circ} \mathrm{C}$ for $2 \mathrm{~h}$; b) FE-SEM of $\mathrm{La}_{0.5} \mathrm{Li}_{0.5} \mathrm{TiO}_{3}: \mathrm{Eu}^{3+}$ (1 at $\left.\%\right)$ powders heated at $800{ }^{\circ} \mathrm{C}$ and c) X-ray diffraction of $\mathrm{Eu}^{3+}$ doped $\mathrm{La}_{0.5} \mathrm{Li}_{0.5} \mathrm{TiO}_{3}$ with different concentrations heated at $800{ }^{\circ} \mathrm{C}$.

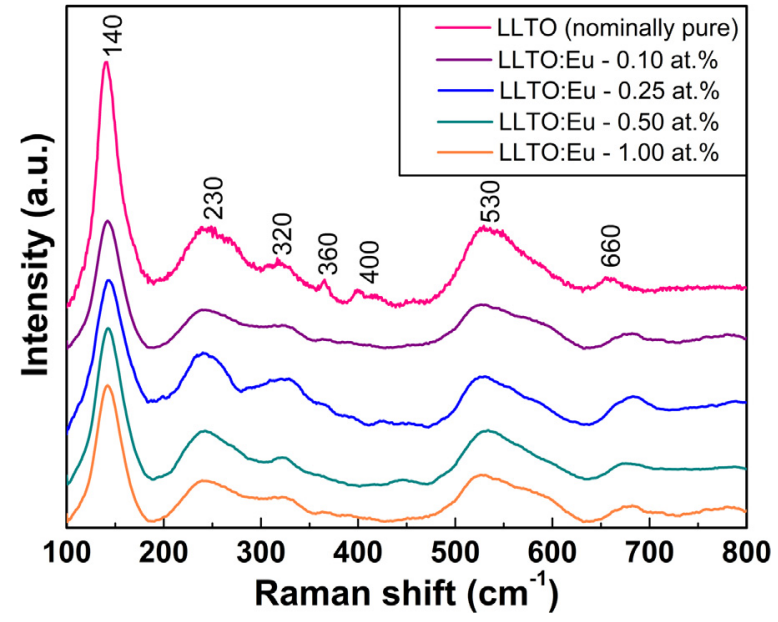

Fig. 3. Raman spectra of non-doped and $\mathrm{Eu}^{3+}$ doped $\mathrm{La}_{0.5} \mathrm{Li}_{0.5} \mathrm{TiO}_{3}$ heated at $800^{\circ} \mathrm{C}$.

the Eu-doped samples, it was possible to observe a decrease of intensity compared to the non-doped samples, which is more evident in the bands located at 360 and $400 \mathrm{~cm}^{-1}$ attributed to the lithium titanate, that almost disappear. Besides that, the presence of europium also promotes the displacement of the bands. This behavior is due to the substitution of A-site by $\mathrm{Eu}^{3+}$ which could affect the motion in the $\mathrm{TiO}_{6}$ octahedra, as observed to $\mathrm{FeO}_{6}$ octahedra in rare earth doped $\mathrm{BiFeO}_{3}$ perovskite [37]. According to Ye et al. in the study of a double-perovskite, the A-site substitution by $\mathrm{Eu}^{3+}$ gives a shift of the peaks, even though the substituted content was small $(\mathrm{x} \leq 0.10)$. When the B-sites are substituted no clear peak shift is observed [38].

The optical band gap energy of the samples was calculated by the application of Wood- Tauc method [38] and the Kubelka-Munk function [39]. This methodology is used to transforms diffuse reflectance measurements into E gap values with high accuracy [40]. Fig. 4, shows the E gap values of pure LLTO and $\mathrm{Eu}^{3+}$ - doped LLTO, where it is possible to note a slight decrease in the optical band gap with the incorporation of $\mathrm{Eu}^{3+}$. The same behavior could be noticed for non-doped $\mathrm{ZnO}$ and $\mathrm{Eu}^{3+}$-doped $\mathrm{ZnO}$ [41]. The different $\mathrm{E}$ gap values obtained indicates the existence of intermediary energy levels between the valence band and conduction band. The increase of the optical band gap values is related to a reduction of the intermediary energy levels between bands due to the reducing the number of defects in the structure of the material, since the optical band gap energy is controlled by the degree of structural order-disorder in the lattice [40]. In this sense, the increase of disorder structural is related to the $\mathrm{Eu}^{3+}$ content, since we can suppose that the more ordered sample is pure LLTO due to the higher band gap value, suggesting a different conformation or a low concentration of energy states between bands [40]. These energy levels are related to structural order-disorder which causes the loss of symmetry between $\mathrm{O}-\mathrm{M}-\mathrm{O}$ bonds $(\mathrm{M}=$ metal) resulting in complex clusters formation [40].

Fig. 5 a shows the emission spectrum of non-doped $\mathrm{La}_{0.5} \mathrm{Li}_{0.5} \mathrm{TiO}_{3}$. PL analyses provide important information concerning the electronic structure of the materials. Here, we can observe a broadband covering the visible electromagnetic spectra within the range of 400-600 nm centered at $450 \mathrm{~nm}$ (blue emission). This feature is likely to be associated with the presence of defects known to be typical of multiphonon and multilevel emission processes [42]. The broadband model suggests that the PL emission presented by semiconductor materials results of electronic transitions due to the distortion in the crystalline lattice [40]. Non-doped $\mathrm{La}_{0.5} \mathrm{Li}_{0.5} \mathrm{TiO}_{3}$ presents structural disorder in the material's lattice promoting the formation of energy states within the band gap, contributing to the broadband emission in their photoluminescence spectra.

PL emission may be attributed to distortions on the lattice, cation or anion vacancies, surface states and quantum confinement [43]. Emission at green/yellow/orange and red region is caused by deep holes and shallow holes are responsible for PL emission at violet and blue region $[44,45]$. Deep levels are generated by intermediary states close to the conduction band, while shallow levels are due to states near the valence band [43].

Thus, in the case of non-doped $\mathrm{La}_{0.5} \mathrm{Li}_{0.5} \mathrm{TiO}_{3}$, the PL band centered at $450 \mathrm{~nm}$ may essentially indicate the contribution of defects results from shallow levels to PL emission. This information may be backed by the deconvolution of the PL band (Fig. 5b) which was carried out using PeakFit program [31] and the Voigt function. It is possible to observe that the major PL band is composed of three bands, two of them corresponding to different energies of violet-blue emission $(440 \mathrm{~nm}$ and $478 \mathrm{~nm}$ ), while the other one is related to emission in green region $(515 \mathrm{~nm})$. Interestingly, this is additional evidence that the shallow defects are responsible for the emission observed in the non-doped $\mathrm{La}_{0.5} \mathrm{Li}_{0.5} \mathrm{TiO}_{3}$ spectrum, since the violet-blue region occupied $80 \%$ of the major PL band coupled with the fact that there is low contribution of emission characteristic of deep defects $(20 \%)$. Since PL emission in semiconductors is results of electronic transition caused by distortion in the crystalline lattice, this behavior can be associated with the lattice distortion caused by the difference in size of $\mathrm{Li}$ and La atoms which 

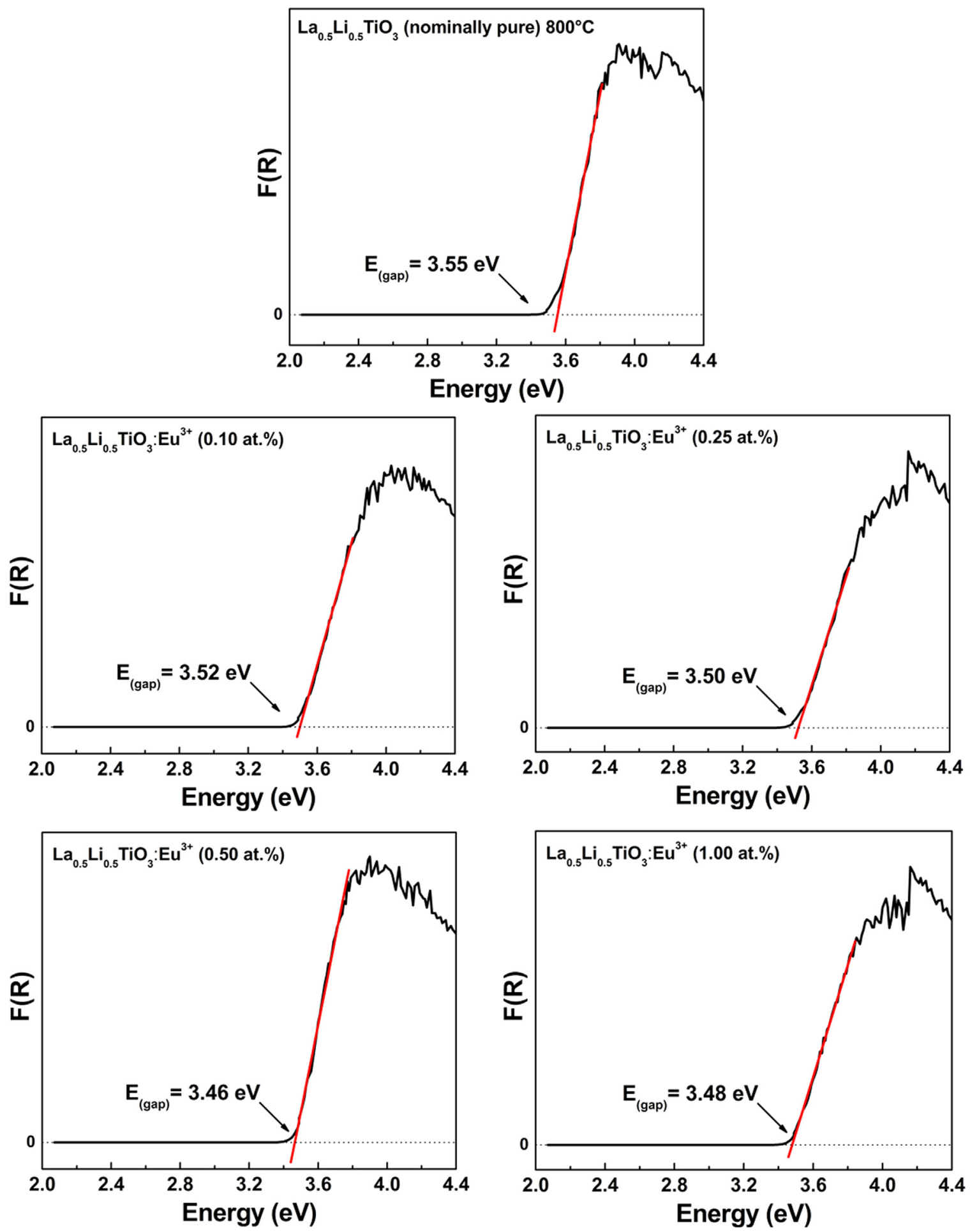

Fig. 4. UV-vis measurements of non-doped and $\mathrm{Eu}^{3+}$ doped $\mathrm{La}_{0.5} \mathrm{Li}_{0.5} \mathrm{TiO}_{3}$ heated at $800{ }^{\circ} \mathrm{C}$.

generate shallow states close to the valence band.

The analysis of the emission spectra of $\mathrm{Eu}^{3+}$ doped materials (Fig. 6a) reveals that the emissions related to the matrix are observed only at lower $\mathrm{Eu}^{3+}$ concentrations. The increase in the $\mathrm{Eu}^{3+}$ content leads to the disappearance of the emission band attributed to the $\mathrm{La}_{0.5} \mathrm{Li}_{0.5} \mathrm{TiO}_{3}$ matrix. When the $\mathrm{Eu}^{3+}$ is present in a greater amount, the relaxation via excitation occurs preferably through the dopant once the $\mathrm{Eu}^{3+}$ emission is favored instead of the matrix emission.

$\mathrm{Eu}^{3+}$ doped compounds present intraconfigurational emissions associated with $4 f^{6} \rightarrow 4 f^{6}$ transitions (Fig. 6b). Regarding the excited level
${ }^{5} \mathrm{D}_{0}$, the lines observed in the spectrum are known to be ${ }^{5} \mathrm{D}_{0} \rightarrow{ }^{7} \mathrm{~F}_{\mathrm{J}}(\mathrm{J}=$ $0,1,2,3,4)$. The lines with $J=5$ and 6 are found to have low intensity and as such were not observed. A further observation worth mentioning is the emission from the higher excited state ${ }^{5} \mathrm{D}_{1} \rightarrow{ }^{7} \mathrm{~F}_{\mathrm{J}}(\mathrm{J}=0,1,2)$. However, transitions starting from ${ }^{5} \mathrm{D}_{2}$ and ${ }^{5} \mathrm{D}_{3}$ excited levels were not observed; when $\mathrm{Eu}^{3+}$ ions are excited to any level above ${ }^{5} \mathrm{D}_{1}$, a fast nonradiative multiphonon relaxation to these levels occurs. Table 1 lists the $\mathrm{Eu}^{3+}$ ions transitions in a $\mathrm{La}_{0.5} \mathrm{Li}_{0.5} \mathrm{TiO}_{3}$ host lattice and the respective wavelength of the emission band.

Given the fact that the levels involved in the transitions are derived 

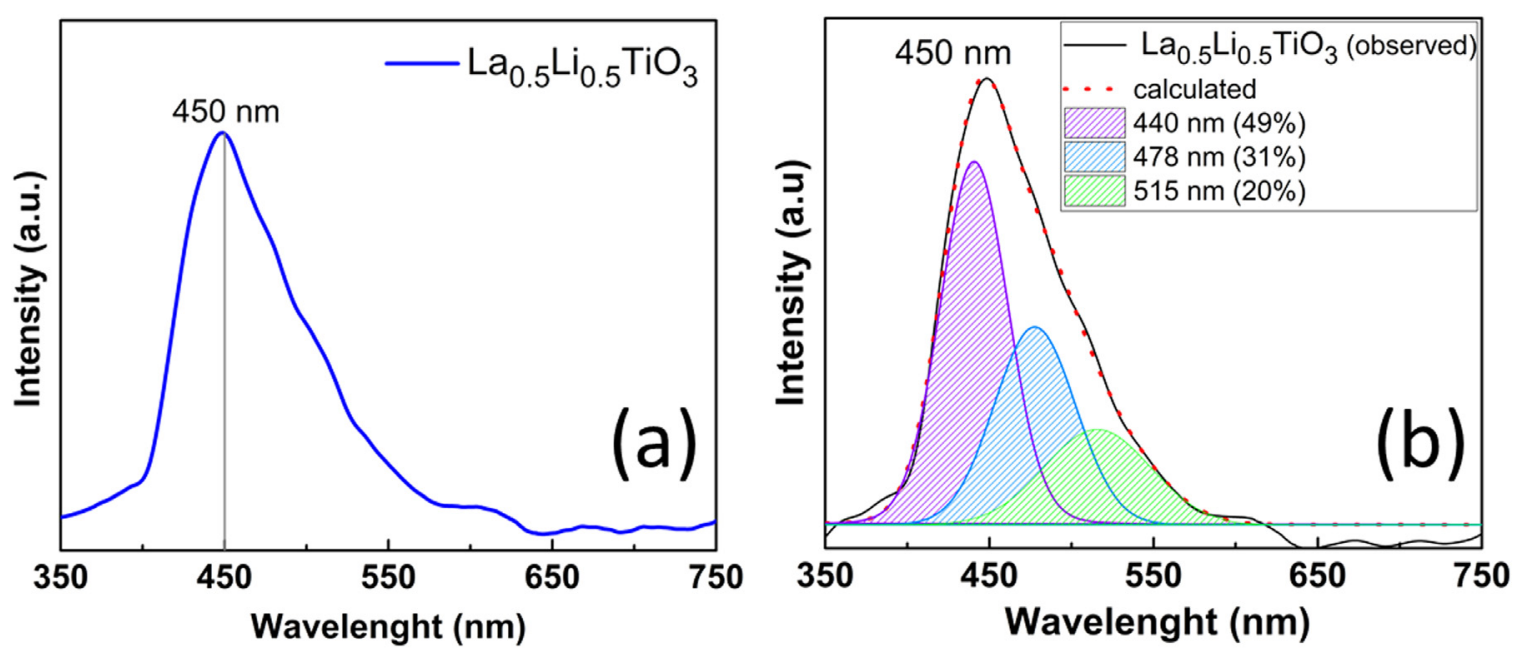

Fig. 5. a) Emission spectra of non-doped $\mathrm{La}_{0.5} \mathrm{Li}_{0.5} \mathrm{TiO}_{3}$ and b) deconvolution of PL band.
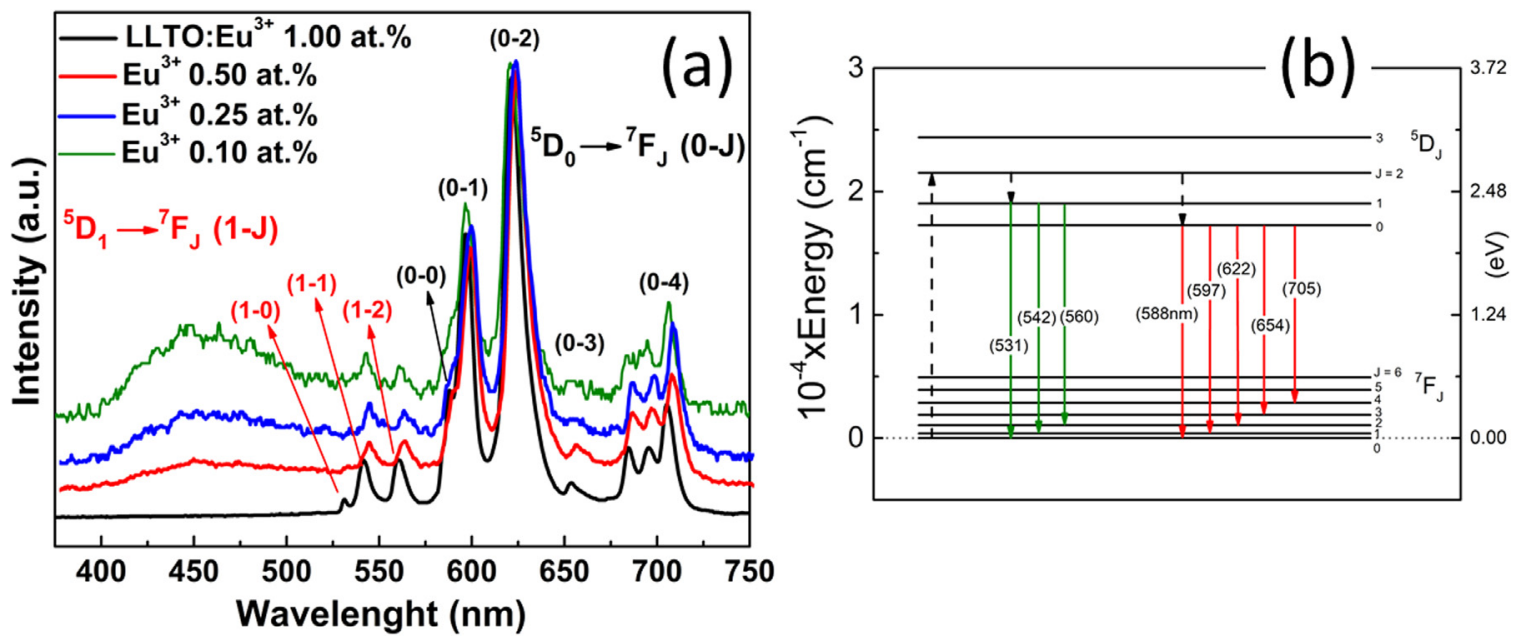

Fig. 6. a) Emission spectra of $\mathrm{La}_{0.5} \mathrm{Li}_{0.5} \mathrm{TiO}_{3}$ heated at $800{ }^{\circ} \mathrm{C}$ and doped at different $\mathrm{Eu}^{3+}$ concentrations from 0.1 to 1 at $\%$ and b) Eu ${ }^{3+}$ transitions.

Table 1

$\mathrm{Eu}^{3+}$ ions transitions in a $\mathrm{La}_{0.5} \mathrm{Li}_{0.5} \mathrm{TiO}_{3}$ host lattice.

\begin{tabular}{ll}
\hline Assignment & Wavelength (nm) \\
\hline${ }^{5} \mathrm{D}_{0} \rightarrow{ }^{7} \mathrm{~F}_{0}$ & 580 \\
${ }^{5} \mathrm{D}_{0} \rightarrow{ }^{7} \mathrm{~F}_{1}$ & 600 \\
${ }^{5} \mathrm{D}_{0} \rightarrow{ }^{7} \mathrm{~F}_{2}$ & 622 \\
${ }^{5} \mathrm{D}_{0} \rightarrow{ }^{7} \mathrm{~F}_{3}$ & 653 \\
${ }^{5} \mathrm{D}_{0} \rightarrow{ }^{7} \mathrm{~F}_{4}$ & $684,696,705$ \\
${ }^{5} \mathrm{D}_{1} \rightarrow{ }^{7} \mathrm{~F}_{0}$ & 530 \\
${ }^{5} \mathrm{D}_{1} \rightarrow{ }^{7} \mathrm{~F}_{1}$ & 541 \\
${ }^{5} \mathrm{D}_{1} \rightarrow{ }^{7} \mathrm{~F}_{2}$ & 560 \\
\hline
\end{tabular}

from the same configuration $\left(4 \mathrm{f}^{6}\right)$, it would be quite expected that all these transitions were forbidden. Nevertheless, the ligand field (odd) associated with the chemical environment where the $\mathrm{Eu}^{3+}$ ion is located has the property of mixing levels of opposite parity settings, relaxing the selection rules for the electric dipole transitions. This fact is reflected in all ${ }^{5} \mathrm{D}_{0} \rightarrow{ }^{7} \mathrm{~F}_{\mathrm{J}}(0-\mathrm{J})$ transitions, being more noticeable in the transition ${ }^{5} \mathrm{D}_{0} \rightarrow{ }^{7} \mathrm{~F}_{2}(0-2)$, which is known to be hypersensitive; and excluding ${ }^{5} \mathrm{D}_{0} \rightarrow{ }^{7} \mathrm{~F}_{1}(0-1)$ which is a magnetic transition [24-30].

The intensity of ${ }^{5} \mathrm{D}_{0} \rightarrow{ }^{7} \mathrm{~F}_{\mathrm{J}}(0-\mathrm{J})$ transitions essentially depends on the symmetry around the $\mathrm{Eu}^{3+}$ ions. When $\mathrm{Eu}^{3+}$ is inserted in high symmetry environments, magnetic dipole transitions ${ }^{5} \mathrm{D}_{0} \rightarrow{ }^{7} \mathrm{~F}_{1}(0-1)$ are found to be predominant. Contrary to that, if $\mathrm{Eu}^{3+}$ occupies a nonsymmetric environment (in other words of low symmetry), electric

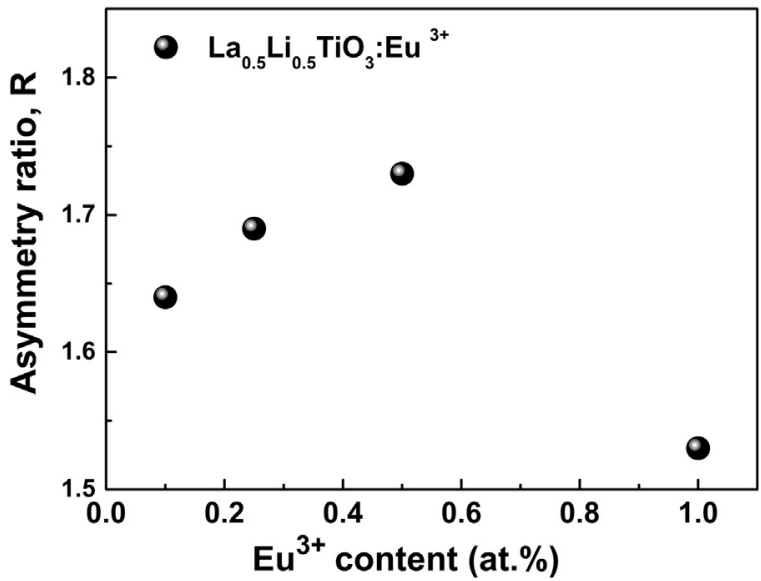

Fig. 7. Asymmetry ratio $\mathrm{R}$ as a function of $\mathrm{Eu}^{3+}$ content.

dipole transitions become largely predominant [30]. As shown in Fig. $4 a$, the $(0-2)$ transitions are relatively more intense $(0-1)$ for all the samples, indicating that $\mathrm{Eu}^{3+}$ doping exhibits a characteristic profile of dopants occupying non-symmetric centers.

The intensity ratio $(0-2) /(0-1)$ is denoted as asymmetry ratio $\mathrm{R}$. The higher the value of $\mathrm{R}$, the larger will be the magnitude of the electric dipole transition and low ligand symmetry, leading to stronger 


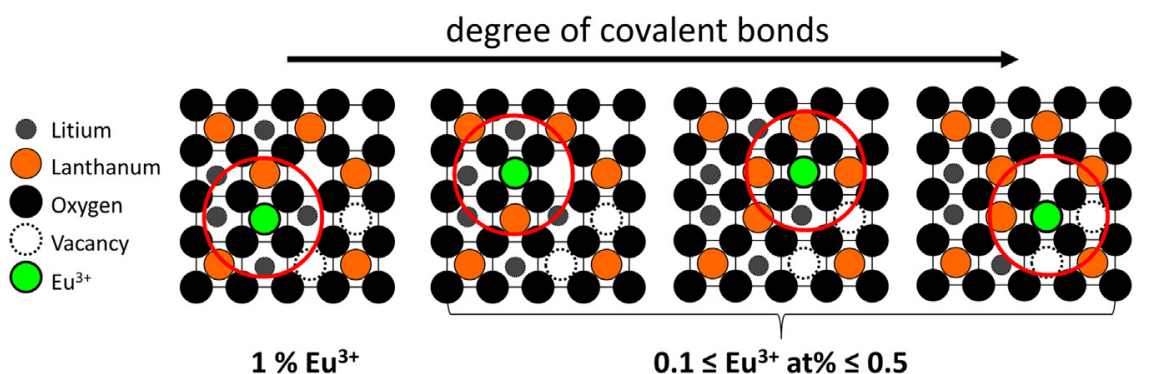

Fig. 8. Diagram representing different chemical environments occupied by $\mathrm{Eu}^{3+}$ identified through the asymmetry ratio, R.

splitting of transitions. The smaller the $\mathrm{R}$ value, the more symmetric is the $\mathrm{Eu}^{3+}$ environment [29]. The asymmetry ratio $\mathrm{R}$ can likewise be used to investigate the relative strength of covalent or ionic bonding of the $\mathrm{Eu}^{3+}$ ions and the surrounding ligands. The higher the value of $\mathrm{R}$, the higher the presence of covalent band and vice versa [29]. In our case, the average of the calculated $\mathrm{R}$ for all the doped samples was 1.65 , confirming the distortion of the local symmetry. Increasing the concentrations of $\mathrm{Eu}^{3+}$ from 0.1 to 0.5 at $\%$ leads to a slight increase in $\mathrm{R}$, from $\sim 1.64$ to $\sim 1.74$, respectively. However, the sample doped with 1 at $\% \mathrm{Eu}^{3+}$ presented the lowest $\mathrm{R}, 1.52$. Fig. 7 illustrates $\mathrm{R}$ as a function of $\mathrm{Eu}^{3+}$ content.

It is known from the complex structure of $\mathrm{La}_{0.5} \mathrm{Li}_{0.5} \mathrm{TiO}_{3}$ that there are many different types of environments that $\mathrm{Eu}^{3+}$ could occupy. The results from photoluminescence spectroscopy suggest that $\mathrm{Eu}^{3+}$ when inserted in the $\mathrm{La}_{0.5} \mathrm{Li}_{0.5} \mathrm{TiO}_{3}$ matrix occupies at least three different chemical environments. Fig. 8 illustrates the different possible settings that $\mathrm{Eu}^{3+}$ may be occupying.

$\mathrm{La}_{0.5} \mathrm{Li}_{0.5} \mathrm{TiO}_{3}$ is an $\mathrm{ABO}_{3}$ type perovskite where the substitution of divalent ions located in sites $\mathrm{A}$ with trivalent ions such as $\mathrm{La}^{3+}$ gives rise to vacancies on sites $\mathrm{A}$. When a percentage number of $\mathrm{La}^{3+}$ ions was replaced by $\mathrm{Li}^{+}$ions, we expected to see the $\mathrm{Li}^{+}$ions occupying sites A of the structure, with a coordination of 12 . Admittedly, $\mathrm{Li}^{+}$is too small to favorably occupy these sites, instead, $\mathrm{Li}^{+}$appears to be located in the interstices of the $\mathrm{ABO}_{3}$ structure. In addition, $\mathrm{La}_{0.5} \mathrm{Li}_{0.5} \mathrm{TiO}_{3}$ structure consists of layers, one being rich in $\mathrm{La}^{3+}$ while the other one is found bearing vacancies of these ions [46]. Thus, when inserted in the structure of $\mathrm{La}_{0.5} \mathrm{Li}_{0.5} \mathrm{TiO}_{3}, \mathrm{Eu}^{3+}$ replaces the $\mathrm{La}^{3+}$ ions, and different chemical environments are observed for $\mathrm{Eu}^{3+}$, originating the ${ }^{5} \mathrm{D}_{0} \rightarrow{ }^{7} \mathrm{~F}_{\mathrm{J}}$ lines.

In summary, the structure presents irregular vacancies of $\mathrm{La}^{3+}$ and $\mathrm{Li}^{+}$occupying the interstices of the structure, which are capable of moving to different chemical environments. All these events are notably associated with the $\mathrm{Eu}^{3+}$ ions distributed throughout the structure of $\mathrm{La}_{0.5} \mathrm{Li}_{0.5} \mathrm{TiO}_{3}$. The samples with $\mathrm{Eu}^{3+}$ inserted in chemical environments which are surrounded by more ionic bonds such as Li-O have lower $\mathrm{R}$ values, whereas samples with $\mathrm{Eu}^{3+}$ inserted in environments with a higher degree of covalent bonds such as La-O present higher $\mathrm{R}$ values. $\mathrm{Li}^{+}$has an ionic radius ranging from 0.6 to $0.9 \AA$ [47], hence when $\mathrm{Li}^{+}$forms a bond with oxygen, the difference in the electronegativity between these two elements renders the Li-O bonds relatively stronger compared to the La-O bonds. The chemical environment noted by $\mathrm{Eu}^{3+}$ when 1 at $\%$ is inserted in the host lattice is surrounded by a greater amount of $\mathrm{Li}^{+}$, comprising at least two or three ions. The degree of covalence in these environments is considered smaller as a result of the lower degree of covalence in the Li-O bonds. A second environment noted by the $\mathrm{Eu}^{3+}$ is likely to have $\mathrm{Li}^{+}$in small quantities, and may even exhibit no Li-O bonds at all. This environment has a higher degree of covalence and it can be observed in samples doped with 0.5 at $\%$.

It is similarly noteworthy that as the $(0-0)$ transition was found to be non-degenerate, the presence of the asymmetric or low symmetric sites occupied by $\mathrm{Eu}^{3+}$ ions was observed for all the samples considered.
Finally, it is important to draw attention to the presence of the transitions related to $\mathrm{D}_{1}$ excited states at 530,540 and $560 \mathrm{~nm}$, corresponding to ${ }^{5} \mathrm{D}_{1} \rightarrow{ }^{7} \mathrm{~F}_{0},{ }^{5} \mathrm{D}_{1} \rightarrow{ }^{7} \mathrm{~F}_{1}$ and ${ }^{5} \mathrm{D}_{1} \rightarrow{ }^{7} \mathrm{~F}_{2}$ respectively. These transitions usually appear in matrices with a very low phonon energy in which the probability of quenching by multiphonon relaxation is relatively low. [29,30]

\section{Conclusion}

In this work, we have demonstrated that at $800{ }^{\circ} \mathrm{C}$ it was possible to obtain $\mathrm{La}_{0.5} \mathrm{Li}_{0.5} \mathrm{TiO}_{3}$ crystalline powders via the Pechini method. The doping was successfully made and no secondary phase regarding the addition of $\mathrm{Eu}^{3+}$ was observed, even increasing the content of the dopant, suggesting that the $\mathrm{Eu}^{3+}$ was inserted in the lattice of the LLTO matrix as a dopant.

By means of morphological analysis, the powder was found to have a large particle size aside from being more agglomerated when doped, suggesting that the addition of $\mathrm{Eu}^{3+}$ favors the sintering process of $\mathrm{La}_{0.5} \mathrm{Li}_{0.5} \mathrm{TiO}_{3}$, which was explained by the introduction of defects into the lattice of the material. This result is in accordance with the UV-Vis measurements, which revealed a small decrease in the gap of the doped materials.

The ratio between the transitions $(0-2)$ and $(0-1)$ obtained by photoluminescence spectroscopy revealed a characteristic profile of $\mathrm{Eu}^{3+}$ occupying low symmetry sites. Furthermore, no changes were observed in the site occupied by $\mathrm{Eu}^{3+}$ in spite of a change in the concentration of the dopant. Our results show that $\mathrm{La}^{3+}$ in the $\mathrm{La}_{0.5} \mathrm{Li}_{0.5} \mathrm{TiO}_{3}$ structure is largely influenced by different types of atoms and neighboring defects.

\section{Acknowledgment}

This work was supported by the Brazilian Funding agencies: Fundação de Amparo a Pesquisa do Estado de São Paulo- FAPESP (2009/ 134651-0 and 2013/07296-2) and CAPES-Coordenação de Aperfeiçoamento de Pessoal de Nível Superior.

\section{References}

[1] Y. Inaguma, M. Nakashima, A rechargeable lithium-air battery using a lithium ionconducting lanthanum lithium titanate ceramics as an electrolyte separator, J. Power Sources 228 (2013) 250-255, https://doi.org/10.1016/j.jpowsour.2012.11. 098.

[2] Y. Liang, L. Ji, B. Guo, Z. Lin, Y. Yao, Y. Li, et al., Preparation and electrochemical characterization of ionic-conducting lithium lanthanum titanate oxide/polyacrylonitrile submicron composite fiber-based lithium-ion battery separators, J. Power Sources 196 (2011) 436-441, https://doi.org/10.1016/j.jpowsour.2010.06. 088.

[3] B. Antoniassi, A.H.M. González, S.L. Fernandes, C.F.O. Graeff, Microstructural and electrochemical study of La0.5Li0.5TiO3, Mater. Chem. Phys. 127 (2011) 51-55, https://doi.org/10.1016/j.matchemphys.2010.12.021.

[4] Y. Inaguma, C. Liquan, M. Itoh, T. Nakamura, T. Uchida, H. Ikuta, et al., High ionic conductivity in lithium lanthanum titanate, Solid State Commun. 86 (1993) 689-693, https://doi.org/10.1016/0038-1098(93)90841-A.

[5] H.T.T. Le, D.T. Ngo, Y.-J. Kim, C.-N. Park, C.-J. Park, A perovskite-structured aluminium-substituted lithium lanthanum titanate as a potential artificial solid-electrolyte interface for aqueous rechargeable lithium-metal-based batteries, 
Electrochim. Acta 248 (2017) 232-242, https://doi.org/10.1016/J.ELECTACTA. 2017.07.110.

[6] X. Han, X. Gui, W. Tao, X. Li, T.-F. Yi, Facile strategy to fabricate Na2Li2Ti6O14@ Li0.33La0.56TiO3 composites as promising anode materials for lithium-ion battery, Ceram. Int. (2018), https://doi.org/10.1016/J.CERAMINT.2018.04.013.

[7] C. Sun, J. Liu, Y. Gong, D.P. Wilkinson, J. Zhang, Recent advances in all-solid-state rechargeable lithium batteries, Nano Energy 33 (2017) 363-386, https://doi.org/ 10.1016/J.NANOEN.2017.01.028.

[8] K.P. Abhilash, P. Christopher Selvin, B. Nalini, K. Somasundaram, P. Sivaraj, A. Chandra Bose, Study of the temperature dependent transport properties in nanocrystalline lithium lanthanum titanate for lithium ion batteries, J. Phys. Chem. Solids 91 (2016) 114-121, https://doi.org/10.1016/J.JPCS.2015.12.015.

[9] D.T. Swamy, K.E. Babu, V. Veeraiah, Evidence for high ionic conductivity in lithium-lanthanum titanate, Li 0.29 La 0.57 TiO 3, Bull. Mater. Sci. Indian Acad. Sci. 36 (2013) 1115-1119 (〈https://www.ias.ac.in/article/fulltext/boms/036/06/ 1115-1119 > (Accessed 15 May 2018)).

[10] T. Teranishi, Y. Ishii, H. Hayashi, A. Kishimoto, Lithium ion conductivity of oriented Li0.33La0.56TiO3 solid electrolyte films prepared by a sol-gel process, Solid State Ion. 284 (2016) 1-6, https://doi.org/10.1016/J.SSI.2015.11.029.

[11] I. Seo, S.W. New, Developments in Solid Electrolytes for Thin-Film LithiumBatteries, in: Lithium Ion Batter. - New Dev., 2012. 〈http://dx.doi.org/10. 5772/29132>.

[12] N.S. Hudak, Lithium-Ion Batteries, 2014. 〈http://dx.doi.org/10.1016/B978-0-44459513-3.00004-2>.

[13] N. Kumagai, J. Kim, Materials for lithium-ion batteries, Lithium 153 (2009) 39-52, https://doi.org/10.1149/1.2138573.

[14] C. Chen, J. Du, Lithium ion diffusion mechanism in lithium lanthanum titanate solid-state electrolytes from atomistic simulations, J. Am. Ceram. Soc. 98 (2015) 534-542.

[15] J. Ibarra, A. Várez, C. León, J. Santamaría, L. Torres-Martínez, J. Sanz, Influence of composition on the structure and conductivity of the fast ionic conductors La2/ $3-x L i 3 x T i O 3(0.03 \leq x \leq 0.167)$, Solid State Ion. 134 (2000) 219-228, https:// doi.org/10.1016/S0167-2738(00)00761-X.

[16] A.D. Robertson, S.G. Martin, A. Coats, A.R. West, Phase diagrams and crystal chemistry in the $\mathrm{Li}+$ ion conducting perovskites, Li0.5-3x RE0.5 $+\mathrm{x}$ TiO3: $\mathrm{Re}=\mathrm{La}$, Nd, J. Mater. Chem. 5 (1995) 1405, https://doi.org/10.1039/jm9950501405.

[17] H. Chung, D. Cheong, The microscopic features of (Li La)TiO3, Solid State Ion. 120 (1999) 197-204.

[18] C.W. Ban, G.M. Choi, The effect of sintering on the grain boundary conductivity of lithium lanthanum titanates, Solid State Ion. 140 (2001) 285-292, https://doi.org/ 10.1016/S0167-2738(01)00821-9.

[19] O. Bohnke, H. Duroy, J.L. Fourquet, S. Ronchetti, D. Mazza, In search of the cubic phase of the Li+ ion-conducting perovskite La2/3-xLi3xTiO3: structure and properties of quenched and in situ heated samples, Solid State Ion. 149 (2002) 217-226, https://doi.org/10.1016/S0167-2738(02)00142-X.

[20] J.A. Alonso, J. Sanz, J. Santamaría, C. León, A. Várez, M.T. Fernández-Díaz, On the location of $\mathrm{Li}+$ cations in the fast $\mathrm{Li}$-cation conductor $\mathrm{La} 0.5 \mathrm{Li} 0.5 \mathrm{TiO} 3$ perovskite, Angew. Chem. - Int. Ed. 39 (2000) 619-621, https://doi.org/10.1002/(SICI)15213773(20000204)39:3<619::AID-ANIE619>3.0.CO;2-O.

[21] M. Crosnier-Lopez, H. Duroy, Y. Calage, J. Greneche, J. Fourquet, New A-deficient perovskites in the series LixLa2/3Ti1-xFexO3 $(0.12 \leq \mathrm{x} \leq 0.33)$ and $\mathrm{La}(2+\mathrm{x}) /$ 3Ti1-xFexO3 (0.5 $\leq \mathrm{x} \leq 1.0$ ), Mater. Res. Bull. 36 (2001) 651-671, https://doi. org/10.1016/S0025-5408(01)00518-9.

[22] Y. Inaguma, T. Katsumata, M. Itoh, Y. Morii, Crystal structure of a lithium ionconducting perovskite La2/3-xLi3xTiO3 $(x=0.05)$, J. Solid State Chem. 166 (2002) 67-72, https://doi.org/10.1006/jssc.2002.9560.

[23] S. Stramare, V. Thangadurai, W. Weppner, Lithium lanthanum titanates: a review, Chem. Mater. 15 (2003) 3974-3990, https://doi.org/10.1021/cm0300516.

[24] J.-J.V.M.D. Marcantonatos, M. Deschaux, Interactions of aqueous 7F and 5D1 Europium (III) ions with bromide and inner-sphere coordination exciplex formation, J. Chem. Soc. Faraday Trans. 2: Mol. Chem. Phys. (1984) 1569-1598.

[25] K. Binnemans, C. Görller-Walrand, Application of Eu3 + ion for site symmetry determination, J. Rare Earths 14 (1996) 173-180.

[26] Y.-S. Chang, H.-J. Lin, Y.-L. Chai, Y.-C. Li, Preparation and luminescent properties of europium-activated YInGe2O7 phosphors, J. Alloy. Compd. 460 (2008) 421-425, https://doi.org/10.1016/j.jallcom.2007.05.060.

[27] C.E. Rodríguez-García, N. Perea-López, G.A. Hirata, S.P. DenBaars, Red-emitting SrIn2O4:Eu3 + phosphor powders for applications in solid state white lamps, J. Phys. D Appl. Phys. 41 (2008) 092005, https://doi.org/10.1088/0022-3727/41/9/
092005.

[28] F.J. De Sousa, G.P.A. De Lima, L.R. Ávila, K.J. Ciuffi, P.S. Calefi, E.J. Nassar, Incorporation of europium III complex into nanoparticles and films obtained by the Sol-Gel methodology, Mater. Res. 13 (2010) 71-75, https://doi.org/10.1590/ S1516-14392010000100015.

[29] S. Arunkumar, K. Marimuthu, Structural and luminescence studies on Eu3 +: B2O3-Li2O-MO-LiF (M = Ba, Bi2, Cd, Pb, Sr2 and Zn) glasses, J. Lumin. 139 (2013) 6-15, https://doi.org/10.1016/j.jlumin.2013.02.014.

[30] M. Venkateswarlu, B.H. Rudramadevi, Spectral analysis of europium doped borate zinc magnesium glass, Int. J. Chem. Tech. Res. 7 (2015) 607-612.

[31] J. Holsa, E. Kestila, Crystal fields in Re of - Eu3 + (Re = La, Gd and Y), J. Chem. Soc. Trans. 91 (1995) 1503-1509.

[32] Method of preparing lead and alkaline earth titanates and niobates and coating method using the same to form a capacitor, 1963. 〈https://patents.google.com/ patent/US3330697A/en〉 (Accessed 4 June 2018).

[33] H.M. Omanda, H. Gnanga, P. Soulounganga, R.O. Ndong, A.E. A-Mvongbote, Z.H. Membetsi, et al., Raman scattering study of La2/3-xLi3x1/3-2xTiO3: relationshp between spectra parameters and amount of lithium, Int. J. Eng. Res. Technol. 3 (2014) 3476-3481.

[34] M.L. Sanjuán, M.A. Laguna, A. Várez, J. Sanz, Effect of quenching on structure and antiferroelectric instability of $\mathrm{La}(2-\mathrm{x}) / 3 \mathrm{LixTiO} 3$ compounds: a Raman study, J. Eur. Ceram. Soc. 24 (2004) 1135-1139, https://doi.org/10.1016/S0955-2219(03) 00581-8.

[35] K. Mukai, Y. Kato, H. Nakano, Understanding the zero-strain lithium insertion scheme of Li[Li 1/3Ti5/3] O4: structural changes at atomic scale clarified by Raman spectroscopy, J. Phys. Chem. C 118 (2014) 2992-2999, https://doi.org/10.1021/ jp412196v.

[36] W. Liu, Y. Wang, X. Jia, B. Xia, The characterization of lithium titanate microspheres synthesized by a hydrothermal method, J. Chem. 2013 (2013) 1-9, https:// doi.org/10.1155/2013/497654.

[37] L.Y. Chang, C.S. Tu, P.Y. Chen, C.S. Chen, V.H. Schmidt, H.H. Wei, et al., Raman vibrations and photovoltaic conversion in rare earth doped (Bi0.93RE0.07)FeO3 $(\mathrm{RE}=\mathrm{Dy}, \mathrm{Gd}, \mathrm{Eu}, \mathrm{Sm})$ ceramics, Ceram. Int. (2015), https://doi.org/10.1016/j. ceramint.2015.09.005.

[38] S. Ye, C.-H. Wang, X.-P. Jing, Photoluminescence and Raman spectra of doubleperovskite $\mathrm{Sr}$ [sub 2] Ca(Mo/W)O[sub 6] with A- and B-site substitutions of Eu[sup 3+], J. Electrochem. Soc. 155 (2008) J148, https://doi.org/10.1149/1.2898897.

[39] D.L. Wood, J. Tauc, Weak absorption tails in amorphous semiconductors, Phys. Rev. B 5 (1972) 3144-3151, https://doi.org/10.1103/PhysRevB.5.3144.

[40] P.F.S. Pereira, A.F. Gouveia, M. Assis, R.C. de Oliveira, I.M. Pinatti, M. Penha, et al., $\mathrm{ZnWO}_{4}$ nanocrystals: synthesis, morphology, photoluminescence and photocatalytic properties, Phys. Chem. Chem. Phys. 20 (2018) 1923-1937, https://doi. org/10.1039/C7CP07354B.

[41] A.F.V. da Fonseca, R.L. Siqueira, R. Landers, J.L. Ferrari, N.L. Marana, J.R. Sambrano, et al., A theoretical and experimental investigation of Eu-doped $\mathrm{ZnO}$ nanorods and its application on dye sensitized solar cells, J. Alloy. Compd. 739 (2018) 939-947, https://doi.org/10.1016/j.jallcom.2017.12.262.

[42] R.F. Gonçalves, A.R.F. Lima, M.J. Godinho, A.P. Moura, J. Espinosa, E. Longo, et al., Synthesis of Pr3+-doped CaTiO3 using polymeric precursor and microwave-assisted hydrothermal methods: a comparative study, Ceram. Int. 41 (2015) 12841-12848, https://doi.org/10.1016/j.ceramint.2015.06.121.

[43] E. Silva Junior, F.A. La Porta, M.S. Liu, J. Andrés, J.A. Varela, E. Longo, A relationship between structural and electronic order-disorder effects and optical properties in crystalline TiO 2 nanomaterials, Dalton Trans. 44 (2015) 3159-3175, https://doi.org/10.1039/C4DT03254C.

[44] J.C. Sczancoski, L.S. Cavalcante, T. Badapanda, S.K. Rout, S. Panigrahi, V.R. Mastelaro, et al., Structure and optical properties of [Ba1-xY2x/3] (Zr0.25Ti0.75)O3 powders, Solid State Sci. 12 (2010) 1160-1167, https://doi.org/ 10.1016/J.SOLIDSTATESCIENCES.2010.04.002.

[45] L.S. Cavalcante, J.C. Sczancoski, F.S. De Vicente, M.T. Frabbro, M.S. Li, J.A. Varela, et al., Microstructure, dielectric properties and optical band gap control on the photoluminescence behavior of Ba[Zr0.25Ti0.75]O3 thin films, J. Sol-Gel Sci. Technol. 49 (2009) 35-46, https://doi.org/10.1007/s10971-008-1841-x.

[46] B. Nalini, Characterization of europium substituted lithium lanthanum titanate, Solid State Ion. 154-155 (2002) 629-634, https://doi.org/10.1016/S01672738(02)00507-6.

[47] R.D. Shannon, Revised effective ionic radii and systematic studies of interatomie distances in halides and chaleogenides, Acta Crystallogr. A32 (1976) 751-767, https://doi.org/10.1107/S0567739476001551. 